New World, and Linnæus's eastern species of 'Gymnothe other hand, the mullet attribution is confirmed by Aristotle's statement that his kestreus had a gizzard-like stomach, which Muraena certainly has not. Page $302 \mathrm{f}$., Aristotle's placental fish was rediscovered by Steno in 1673 before J. Müller. Page 390 , footnote $g$, includes a misprint which is good Scots, but not what Dr. Peck meant to say. But slips like these do not detract from the essential importance of the work, even if it is not ungracious to mention them, and all students of the history of biology will be deeply grateful to the author for an outstanding addition to Aristotelian literature.

F. J. COLE. tus' could scarcely have been known to Aristotle. On

meated by what one may call the 'research spirit', and the authors say in the preface that it contains much information from their own experience.

The fifth and sixth groups of the Periodic Table contain some of the most interesting elements, and this applies also to the metals, which the authors, unfortunately, have not been able to include in the book.

Whether for its well-conceived and executed plan, or for its objective tone, the book deserves very high praise indeed, and will undoubtedly take its place in the list of books every chemist will wish to possess. The printing, paper and binding are worthy of the text.

\section{THE RELATION OF BODY AND MIND}

\section{Food for Thought}

A Treatise on Memory, Dreams and Hallucinations. By Bernard J. Duffy. Pp. 160. (London, New York and Toronto: Longmans, Green and Co., Ltd.; Dublin : Abbey Publishers, 1944.) 10s. 6d. net.

Systematic Inorganic Chemistry of the Fifth- and Sixth-Group Nonmetallic Elements

By Prof. Don M. Yost and Horace Russell, Jr. (Prentice-Hall Chemistry Series.) Pp. $\mathrm{xx}+423$. (New York: Prentice-Hall, Inc., 1944.) 6 dollars.

RY selecting a rather small but highly interesting Band important part of the chemistry of the elements, the authors have been able to give, in a short compass, a very valuable survey of topies which should be of the highest value to students and teachers, and also, since adequate references to literature are given, to those seeking further information on the subjects with which it deals. Particular emphasis is laid on such modern aspects as molecular dimensions and shapes, and bond-lengths, and there are usually rather full statements of all the quantitative properties of the substances dealt with.

It is clear that the authors have made very full use of the original literature, and have provided concise yet highly informative summaries of a large number of papers. As an example, the fifteen-page account of the metaphosphates may be mentioned, this including all the results of a large amount of difficult literature in a clear, ample and readable form. The treatment is critical without being obtrusively so. There are many good graphs of properties and diagrams of molecular structures; but the book as a whole is rather weak on preparative chemistry, and the reviewer missed diagrams of apparatus even in cases, such as the description of the preparation of hydrogen persulphides, where these are essential in appreciating the methods.

Some matter which could well be omitted from such a book, such as the half-page dealing with the theory of electron gas on p. 141, would, in the reviewer's opinion, better have been replaced by preparative detail, but this is perhaps a point on which opinions will differ. In the description of the glow of phosphorus (p. 170) sufficient emphasis is not given to the work of Miller, quoted on p. 177 ; this section should be revised in a new edition. The reviewer noticed very few misprints; "Bayley" instead of Baly on p. 4, and $\mathrm{H}_{2} \mathrm{PO}_{3}$ instead of $\mathrm{H}_{3} \mathrm{PO}_{3}$ in the heading on p. 198, are examples of what can be put right in a later edition, and the text seems remarkably accurate. The book is very well written, the interest being maintained even in sections containing mostly numerical data, and students should find it stimulating and arousing interest in the subject. It is per-
THE evidence in favour of telepathic communication (supra-normal cognition or extra-sensory perception) is now enough, and more than enough, to convince any reasonable inquirer, and it may be time to consider theories to explain how it happens. A theory of physical transmission from agent to recipient, that is capable of experimental test by ordinary methods of scientific investigation, is to be preferred if it is at all possible, to any theory that cannot be tested in this way. Indeed, for those who hold that everything must have a physical explanation, such a theory is urgently needed.

Mr. Duffy puts forward a hypothesis of the relation of body and mind that belongs to the same genus as that of Descartes; namely, that mental processes are activities of a spiritual substance distinct from the bodily organism, but interacting with it through a specific physical mechanism. The mechanism Mr. Duffy suggests is that active brain cells produce weak radiation of wave-lengths about the range of the shortest used for radio transmission. Normally, each mind interacts with its own brain, but exceptionally with another; hence telepathy. The evidence quoted for the existence of such radiation is not convincing, but it seems a possibility, and it is almost certainly the last hope of a physical explanation of telepathy. There seems to be no reason why chemical reactions in nerve cells should not produce weak rays of wave-length between a metre and a micron; why radiation from a group of cells should not form a beam; why it should not be projected to great distances. On this hypothesis, telepathic reception should be highly localized; agent and recipient could be screened from one another; artificial production of rays of appropriate wavelength should have striking results. All these suppositions can be tested.

There are serious objections to any type of Cartesian theory of the body-mind relation, which even $\mathrm{Mr}$. Duffy's ingenious suggestions do not overcome. There are considerable objections to any radiation theory of telepathic transmission. Still, an improbable theory which can be tested has a scientific value so long as it has not been disproved, and no theory in this sphere starts with any high probability. Mr. Duffy's theory, therefore, deserves serious consideration.
A. D. Ritchie. 